\title{
A new evaluation system to estimate the impact of Coal Seam Gas activity on economic returns of agriculture
}

\author{
$\underline{\text { O. Marinoni }}^{\text {a }}$ and J. Navarro ${ }^{a}$ \\ ${ }^{a}$ CSIRO Land and Water Flagship, Dutton Park, Queensland, Australia \\ Email: oswald.marinoni@,csiro.au
}

\begin{abstract}
There is an ever growing demand for energy worldwide and the demand for gas alone is predicted to double between 2010 and 2035. This demand together with concurrent advances in drilling technologies caused the production of unconventional natural gas such as shale gas and coal seam gas (CSG), which is in the focus of this paper, to grow rapidly in the last decades. With the gas bearing coal seams extending across vast areas within their respective basins and with CSG production having to follow these seams through a network of production wells, pipelines and access roads, CSG activity affects large areas and therefore interferes with existing land uses predominantly agriculture. For the eastern Australian Surat Basin and the southern Bowen Basin alone there are projected active well numbers in excess of 15,000 to 20,000 between the years 2020 and 2030. The spatial overlap of CSG with agricultural land use on a large scale has raised concerns about the impact of CSG on farmland, food security, water resources and the socio-economic environment within the affected regions and beyond. This paper presents a newly developed GIS based model which provides order of magnitude figures of the impact of CSG activity on the economic returns of current agricultural land uses in a given region over the time of CSG production and beyond. The model is capable to account for a variation in a variety of parameters including the number of local impacts caused by repeated work-overs of CSG wells, differences in soil types and associated varying responses of soil productivity, varying length of the CSG production phase and more. The model is flexible in that it can be transferred and applied to other regions. Based on a literature research and given that CSG is an industry that started operating at larger scales relatively recently, we claim that the presented model is the first of its kind to provide these important agro-economic indicators for a mining operation at this large scale.
\end{abstract}

Keywords: Coal Seam Gas, CSG, economic impact, agriculture, mining 
The demand for energy is growing worldwide. The demand for gas alone is predicted to double between 2010 and 2035 (Lyster, 2012). This ever growing demand as well as advances in drilling technologies caused the production of unconventional natural gas such as shale gas and coal seam gas (CSG) to grow rapidly in the last decades. CSG resources in eastern Australia are to complement the conventional, largely offshore, gas resources (AL Jaques et al., 2010) and annual CSG production in Australia increased from 1 PJ in 1996 to $240 \mathrm{PJ}$ in 2010-11 (Geoscience Australia, 2012). With estimated Economic Demonstrated Resources (EDR) of around 35,900 PJ and taking the 2010-11 production rates as a baseline CSG reserves can be projected to last some 150 years. This does not account for Australia's substantial sub-economic demonstrated resources of 65,500 PJ and "very large" inferred CSG resources (Geoscience Australia, 2012). Of the 35,900 PJ in EDR, some 92\% (or 33,000 PJ) are in Queensland and the remaining 2,900 PJ in New South Wales. Nearly all current reserves are contained in the Surat $(69 \%)$ and Bowen $(23 \%)$ basins with smaller amounts distributed across basins in New South Wales. With the gas-bearing coal seams extending across vast areas within their respective basins and with CSG production having to follow these seams through a network of production wells, pipelines and access roads, CSG activity affects large areas and therefore interferes with existing land uses predominantly agriculture. This paper presents a new model that accounts for the diversity of impact characteristics related to CSG infrastructure on agricultural returns.

\subsection{Study area}

The Surat basin is a geological basin which covers considerable areas of northern New South Wales and southern Queensland. CSG is produced from multiple coal seams across the Middle Jurassic Walloon Subgroup (Hamilton et al., 2012) and petroleum leases have already been approved for tenements covering over $24,000 \mathrm{~km}^{2}$ of the Surat basin. Tenements are held by a variety of resource companies. The study area is located in the central Condabri gas development area where Australia Pacific Liquefied Natural Gas (APLNG) holds the permit to extract gas for a variety of tenements (Figure 1).

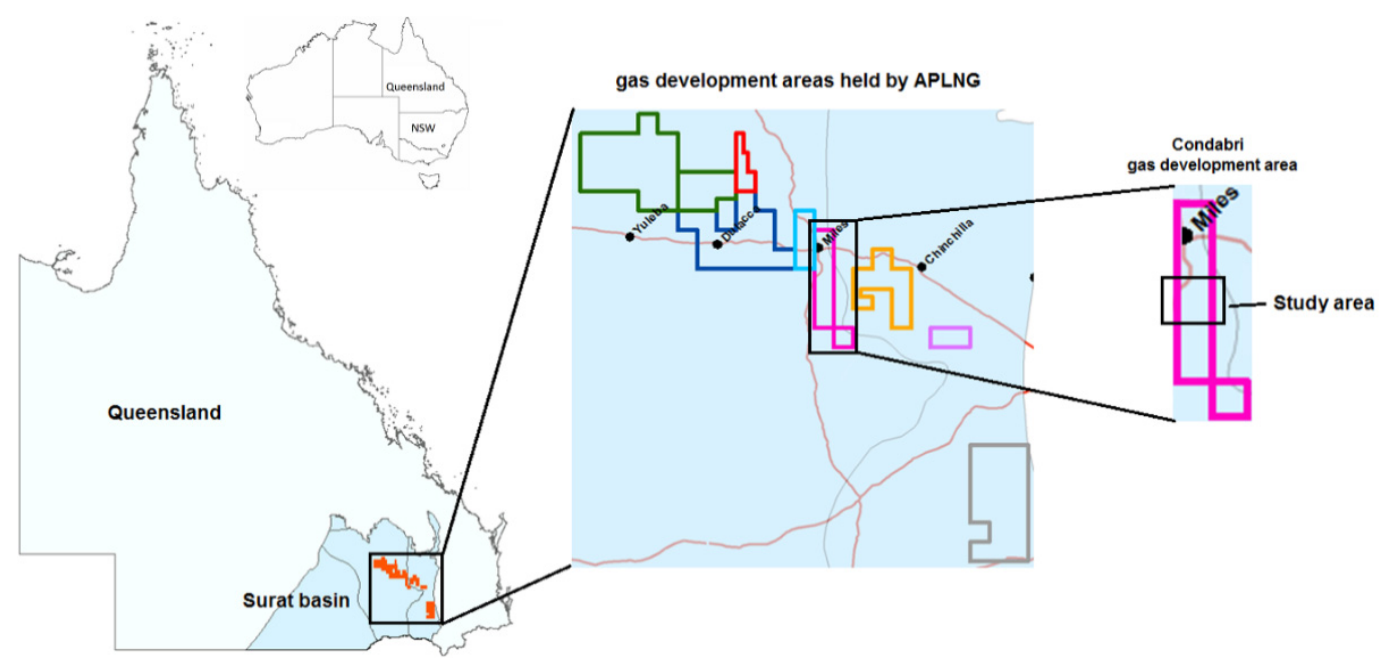

Figure 1. APLNG tenements in the Queensland part of the Surat basin. Study area is in the central part of the Condabri gas development area.

\subsection{CSG infrastructure}

CSG infrastructure usually consists of a network of well pads inserted into the landscape at a density of approximately 1 to 2 per square kilometre (Huth et al., submitted). Servicing these wells is a network of access roads, pipelines for gas and water, and electrical power supply. In addition there are also more than $4000 \mathrm{~km}$ of transmission pipelines to connect producing gas fields to local and export markets (Huth et al., submitted). Figure 2 shows the CSG infrastructure network within the study area. 


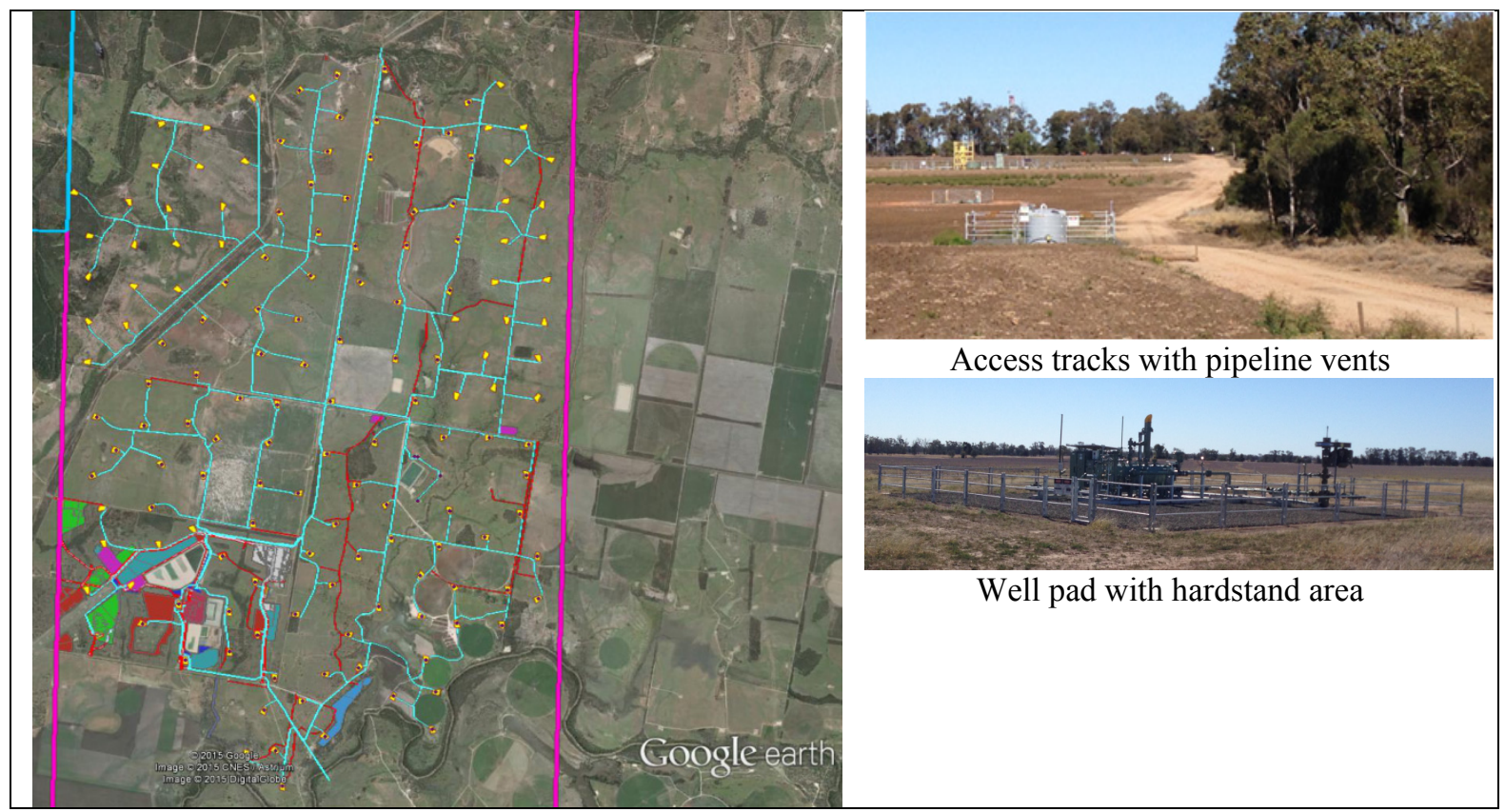

Figure 2. Left: CSG infrastructure network in the study area consisting of well pads, access tracks, gas treatment and water treatment facilities in the study area. E-W width of the development area ca. $8.3 \mathrm{~km}$, NS extent of the study area approx. 12km. Right: Example of an access track and a well pad in the field.

\subsection{Spatial footprint of infrastructure elements and impact on agricultural returns}

The impact assessment is based on the fact that the footprint of CSG infrastructure, a well pad for instance, removes land from agricultural production. Thus, for as long as an infrastructure element exists, economic returns in $(\$ / \mathrm{ha})$ are reduced and production in tonnes $(\mathrm{t})$ is lost. While the size of the footprint is an important factor that drives the magnitude of the impact; there are other factors that need to be considered such as

1. Change of land use. CSG infrastructure intersects with a variety of agricultural land uses where each land use has a specific return ( $\$ /$ ha, tonnes of a commodity produced).

2. Diversity of CSG infrastructure elements. There is not only one but a variety of CSG infrastructure elements that need to be considered (access tracks, well pads, pipelines etc.).

3. Diversity of impact "signature". CSG infrastructure elements have distinct impact signatures not only in terms of the spatial footprint but also in term of impact time, magnitude and frequency

4. Changes in the biophysical environment. Infrastructure elements as well as land uses do spatially intersect with a variety of soil types where each soil type is not only different in terms of productivity and economic returns but also reacts different to impacts.

The authors are aware that there is a range of additional factors related to CSG production which impact agricultural activity and productivity. These include e.g. interruption of farming operations, dust generation, changes to the run-off etc. all of which are not captured by the model.

\subsection{Soil recovery}

During construction of CSG infrastructure heavy machine equipment is used which disturbs the existing soil texture through compaction which is equivalent to decreasing soil porosity. This impacts productivity in that it limits access to water and nutrients and makes it harder for seedlings to grow. Impacts of compaction on soils are well studied and soil compaction is generally considered a problem if not a threat to agriculture (Duiker, 2004; Hakansson, 1994; Hamza and Anderson, 2005). It is known that soils have a certain capacity to reverse compaction (through wetting-drying, freeze-thaw cycles) but this process is slow. Duiker reported a 3\% yearly decrease in yield losses on a soil compacted by a 10 ton axle load. Antille et al. (2014) reported a $50 \%$ decrease in productivity in CSG areas impacted by compaction whereas previously compacted but rehabilitated soils achieved values around $90 \%$ of the original productivity. In Queensland, mining operators are required by law to rehabilitate all areas of disturbance caused by their operations (Queensland Government, 1994). The model currently considers a linear rate of soil recovery only but other non-linear recovery functions can be integrated. 
There is no impact pattern which could be applied across all CSG infrastructure elements and even elements that serve the same purpose can have different impact characteristics. For example, the development of a gas field requires lots of new access tracks to be built. If these tracks are newly built on agricultural land the area across which these new track are built is taken off production. Concurrently, there exist access tracks that are used as such by CSG activity but had existed before CSG production started. Already existing tracks can therefore not be attributed to the spatial footprint associated to CSG. Thus, even though spatial elements may have the same purpose their impact "history" may be fundamentally different. To account for these differences a list of impact categories was developed (Table 1). Given the access track example above, preexisting access tracks would have to be assigned to a different impact category than newly established ones. It also matters if an access track will be rehabilitated after CSG production finishes or if it is kept and rehabilitated after $\mathrm{CSG}$.

Table 1. Impact categories for CSG infrastructure elements.

\begin{tabular}{|c|c|c|}
\hline $\begin{array}{c}\text { ID } \\
\text { Impact } \\
\text { Category }\end{array}$ & Impact description & Remarks \\
\hline 0 & $\begin{array}{l}\text { Element already existed before } \\
\text { CSG activity }\end{array}$ & $\begin{array}{l}\text { As elements had already existed before CSG (e.g. existing tracks across properties) the } \\
\text { direct spatial footprint of these elements cannot be attributed to CSG }\end{array}$ \\
\hline 1 & $\begin{array}{l}\text { Impact over lifetime of CSG } \\
\text { production and beyond }\end{array}$ & $\begin{array}{l}\text { Elements built for CSG are permanent and will not be removed after CSG; e.g. if a } \\
\text { land owner does not wish that a specific access track is removed }\end{array}$ \\
\hline 2 & $\begin{array}{l}\text { Impact over lifetime of CSG } \\
\text { production only - with subsequent } \\
\text { recovery }\end{array}$ & $\begin{array}{l}\text { Elements are established for CSG production and are used over the lifetime of CSG. } \\
\text { Infrastructure elements will be removed after CSG and affected areas will be } \\
\text { rehabilitated. }\end{array}$ \\
\hline 3 & $\begin{array}{l}\text { Impact at the beginning of CSG } \\
\text { with rehabilitation after impact }\end{array}$ & $\begin{array}{l}\text { Land that is accessed once to establish CSG infrastructure and which is subsequently } \\
\text { rehabilitated and made accessible to agriculture (e.g. digging a trench of a pipeline) }\end{array}$ \\
\hline 4 & $\begin{array}{l}\text { Impact at the beginning of CSG } \\
\text { with subsequent repeated impacts } \\
\text { over the lifetime of CSG }\end{array}$ & $\begin{array}{l}\text { Land is accessed and used to establish an infrastructure element. Over the lifetime of } \\
\text { CSG, this land is repeatedly accessed (and therefore repeatedly impacted) to maintain } \\
\text { infrastructure; for instance areas around well pads that need to be accessed for a well } \\
\text { work over }\end{array}$ \\
\hline
\end{tabular}

\subsection{Impact profiles}

Figure 3 shows a schematic example of an impact category 2 (Table 1) impact signature which can be used to estimate losses to agricultural production. Category 2 represents infrastructure elements that are removed and rehabilitated after CSG production. The assumed lifetime of CSG production is 20 years. A value of $100 \%$ on the chart on the left hand side of Figure 3 Figuremeans that a piece of land is fully impacted in that it cannot contribute to production (note that the associated productivity profile on the right has values of $0 \%$ for the same period). After CSG production has finished the soil is rehabilitated and accessible to agriculture so that the impact consequently drops to $0 \%$. Due to the rehabilitation measures productivity bounces back (here to an assumed value of $75 \%$ of the soil's original productivity) and gradually recovers in time (assuming a linear recovery) to its original productivity or close to it. In this schematic example the original productivity is achieved after some 15 years after CSG production finished. This means that productivity impacts, even though diminishing in time, may go well beyond the lifetime of CSG production itself.

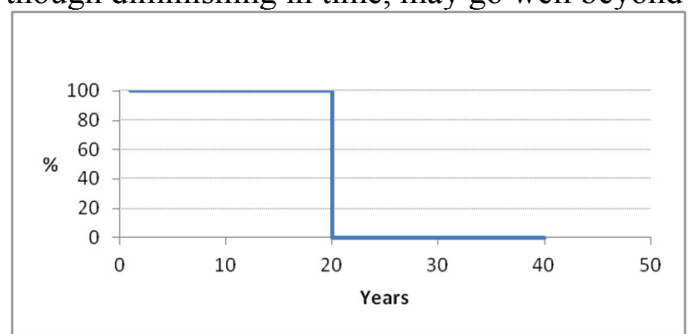

Temporal impact footprint of an access track that is rehabilitated after 20 years

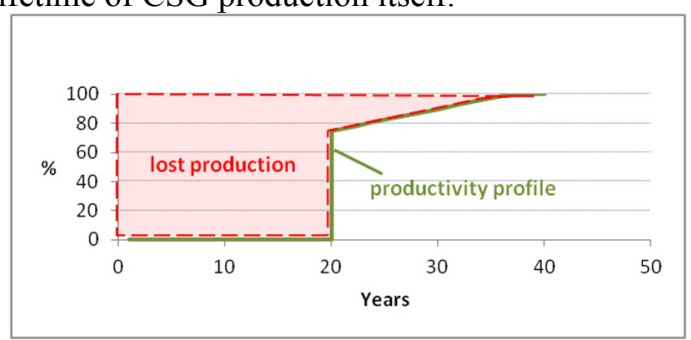

Associated productivity profile with loss area (shaded and dashed outline)

Figure 3. Example impact profile for impact category 1 and associated productivity profile which captures the losses to agricultural production. See text for explanations.

Losses attributed to the impact are represented in the area above the productivity profile (dashed outline, Figure right). These losses are estimated using the area of the impacted area (ha) and information about the land use before CSG and available data on the regional average returns ( $\$ /$ ha) associated to this land use or the commodity produced, respectively.

It is highlighted here that the model as is provides a prognostic assessment over the lifetime of CSG production. It is known that some infrastructure elements will have to be re-accessed by heavy machine 
equipment for maintenance. This predominantly affects the areas around well-pads, so called lease areas, which is a standard area of about 1 ha in size around the well-pads (well-pads are a few hundred $\mathrm{m}^{2}$ in size). Due to slightly varying geological conditions it is and remains unknown when and how many repeated impacts individual well-pads and lease areas will have during CSG production. At the moment impact frequencies are parameterised in the model and generic values are assigned across all infrastructure elements of one kind. For the lease areas for example model runs are performed using impact frequencies of 2, 5 and 15 which provides order of magnitude impact values under favourable well conditions (2), average conditions (5) and conditions that require a work-over nearly every year (15). Another approach would be to integrate data based upon CSG production experience or field observations. If for example average (or upper and lower bounds) impact frequencies and percentages of affected wells were known for certain areas of the Surat basin these values could be used in a simulation. This simulation could repeatedly randomly pick a certain percentage of wells, assign an impact frequency and re-compute impacts on agricultural returns. Simulation functionality is not yet implemented in the model but it is technically no problem to extend the model. However with CSG production having started relatively recently there are yet no reliable average impact figures or portions of affected wells within the study area available.

SPATIAL ANALYSIS

3.1

\section{Data layers}

The digital data layers used include information about land use, soil types, good quality agricultural land (GQAL), strategic cropping land (SCL), cadastral information, information about CSG infrastructure as well as economic layers which capture the average returns in $(\$ / \mathrm{ha})$ for a specific agricultural land use in the study area. The biophysical and administrative information was sourced from Queensland government websites. CSG infrastructure data were obtained from the CSG producer (APLNG). Economic layers for the region were estimated using time series agricultural statistics on commodities and land use that were processed in a system to produce a national map of agricultural profit (Marinoni et al. 2012). Table 2 gives an overview of the data that were used and provides information as to where data were sourced from.

Table 2. Data layers in the study including their sources. All data are vector data except for the economic layer which is in raster format.

\begin{tabular}{ll}
\hline Data layer & Source \\
\hline CSG development areas & \\
Strategic cropping land (SCL) & Qld Government websites \\
Good quality agricultural land (GQAL) & \\
Soil types & \\
Cadastral information & own data (CSIRO) \\
Land use & \\
\hline Data on economic returns and productivity for specific land uses and & \\
commodities in the area & \\
\hline CSG infrastructure & \\
$\bullet \quad$ Well locations (hardstand area) & \\
$\bullet \quad$ Pease areas & CSG producer (APLNG) \\
$\bullet \quad$ Access roads & \\
$\bullet \quad$ Vents along pipelines & \\
$\bullet \quad$ Dams and water ponds & \\
$\bullet \quad$ Gas treatment facility (GTF) & \\
$\bullet \quad$ Main pipeline & \\
\hline
\end{tabular}

\subsection{Spatial operations}

The spatial analysis process involves a train of spatial operations on the digital layers, predominantly intersect operations (Figure 4) where CSG infrastructure is spatially intersected with administrative, biophysical and economic layers. Spatially intersecting features is equal to breaking target features (the infrastructure features) apart. These breakages happen along spatial boundaries that intersect with the target features while all attributes are carried over. This means that the total spatial extent of target features does not change but its representation does in that when being broken up, the total number of infrastructure features increases. Because attributes are carried over it is possible to associate and query information that is specific to parts of the original feature only. 


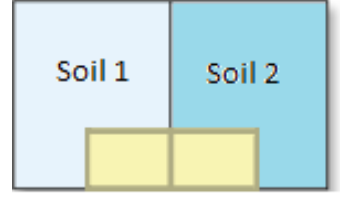

Input

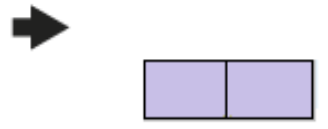

Result

Figure 4. Break-up of one infrastructure element along the boundary of two soils types with an intersect operation. The result on the right hand side shows that the original single feature infrastructure element is broken apart in two features (soil attributes will be carried over to each part of the infrastructure element).

Performing these intersect operations along the layers given in Table 2 ensures that attributes for land use, soil type, quality of the agricultural land, strategic cropping lands etc. will be carried over to each individual feature of the CSG infrastructure. This makes sure that elements can subsequently be queried along a variety of attributes; for example losses incurred by a particular infrastructure on a particular soil type etc.

\subsection{Code component}

Once the spatial operations are finished the original infrastructure features are broken up forming a new feature class that covers the same area however with a much larger number of feature parts than the original feature class. Software code now accesses the attribute table of the newly created feature class and performs a set of operations and computations to provide an estimate of the impact of the infrastructure elements on agricultural returns. Before these computations are being performed, the code needs to read some parameter tables that provide the data for the assumed length of the CSG production period, soil recovery parameters, impact frequencies, discount rate etc. With no simulation functionality yet embedded, a new model run requires the parameters to be changed manually. The code is run in a console application that was coded in .Net 2012.

\section{RESULTS PRODUCED}

For brevity only one set of results can be shown here. As each infrastructure feature (=one record in the feature class's table attribute table) has all associated spatial information (type of infrastructure element, land use, soil type etc.) as well as the computed impacts on economic returns, the table can be queried across various spatial entities and sub-entities therein. For example, results can be provided for individual infrastructure elements but can also be provided for infrastructure elements on specific soil types only. Figure shows the contribution of infrastructure elements to the estimated losses to agricultural revenues and the losses that occur on strategic and non-strategic cropping land respectively. There is a range of parameters the shown results are based upon. These include the duration of the CSG production period (20 years), soil recovery (linear model with a 5 year recovery period), discount rate $(5 \%)$, number of impacts on lease areas ( 2 impacts) and all access tracks had to be established for the CSG activity. A change to any of these parameters will lead to different results. The range of potential outcomes by changing these parameters will be explored through a set of scenarios.
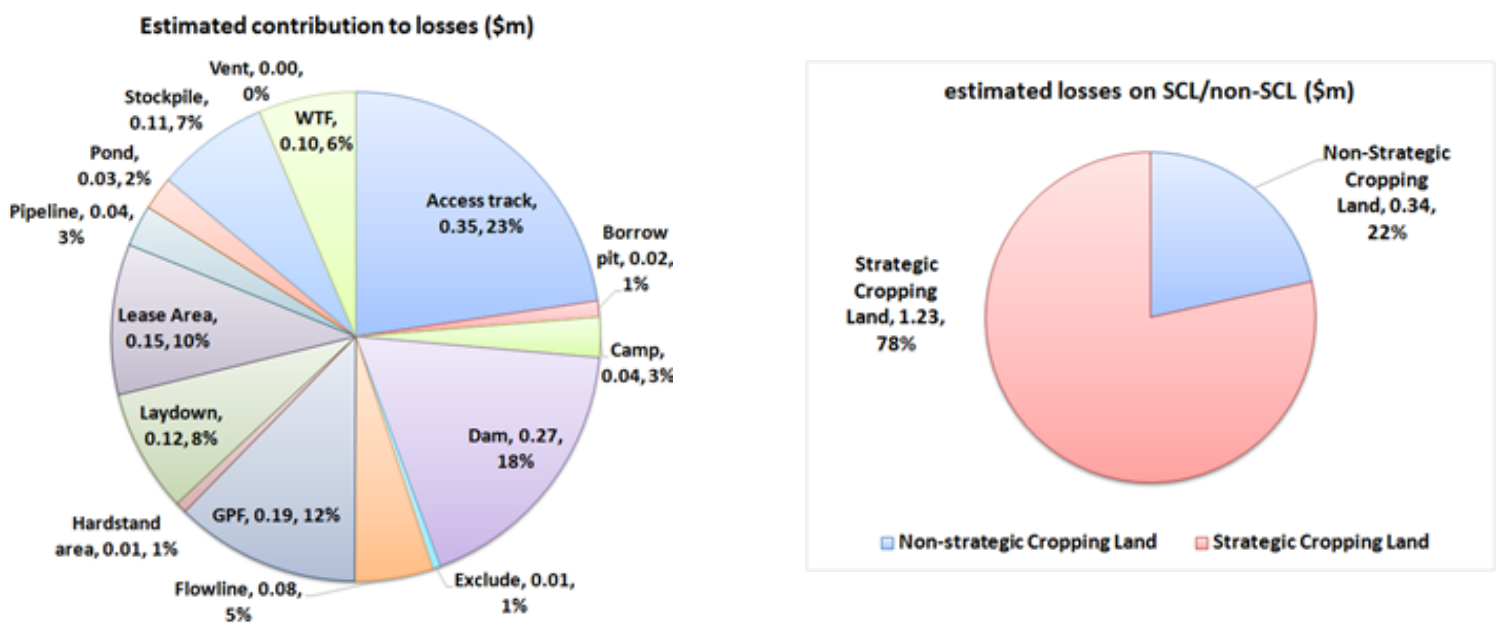

Figure 5. Examples of results produced. Left: Contribution to losses by CSG infrastructure element. Right: losses incurred on strategic/non-strategic cropping land (SCL). 
This paper presents the first system of its kind that assesses impacts of large scale mining activity on agricultural returns. The parameters the model bases its computations on are quite uncertain which is currently accommodated for by running distinct model scenarios based on average as well as upper and lower value bounds of the parameters that are subject to change. To obtain a better understanding of the possible range of the magnitude of impacts a simulation based approach needs to be implemented. This would also include the incorporation of knowledge that will be gained in this specific geological environment after CSG will have operated for a couple of years. This knowledge will include for instance, an order of magnitude value for the number of times a certain fraction of wells need to be accessed for a well work-over. The authors are also aware that there are a variety of impacts that the model does not consider at the moment. These include: effects of the infrastructure to the hydrological run-off which in turn changes the erosional pattern which can impact agricultural productivity. Also not included are impacts of dust generation caused by increased traffic along access tracks. While CSG operators aim to minimise these impacts by management rules and staff training, the effectiveness of these measures should be monitored in time though. Furthermore, there are inconvenience issues affecting the operation of a farm, new obstacles farmers need to navigate around and more which are not implemented but add to the total impact of CSG infrastructure on agriculture and its returns.

\section{ACKNOWLEDGEMENTS}

We would like to acknowledge the Gas and Industry Social and Environmental Research Alliance (GISERA) for funding this research. We would also like to thank APLNG for the provision of CSG infrastructure datasets.

\section{REFERENCES}

Al Jaques, A Ball, M.B., A Budd, L Carson, A Copeland, C Cuevas-Cubria, L Hogan, M Hughes, D Hutchinson, I Lambert, M Lampard, S Lepoidevin, A Maliyasena, A Mckay, J Melanie, Y Miezitis, R New, R Petchey, R Sait, S Sandu, andZhu, R., 2010: Australian energy resource assessment 2009. 140.

Antille, D.L., Eberhard, J., Huth, N.I., Marinoni, Cocks, B., Schmidt, E., 2014. The effects of coal seam gas infrastructure development on arable land. Final Report Project 5: Without a trace. Gas Industry Social and Environmental Research Alliance (GISERA): Canberra, Australia.

Duiker, S.W., 2004: Effects of Soil Compaction. PENNSTATE College of Agricultural Sciences Agricultural Research and Cooperative Extension, 12.

Geoscience Australia, 2012: Australian Gas Resource Assessment 2012. In Department of Resources, E.a.T., Geosceicne Australia, Bureau of Resources and Energy Economics (ed) Canberra, Commonwealth of Australia, 56.

Hamilton, S.K., Esterle, J.S., Golding, S.D., 2012. Geological interpretation of gas content trends, Walloon Subgroup, eastern Surat Basin, Queensland, Australia. International Journal of Coal Geology 101, 21-35.

Hakansson, I., 1994: Subsoil Compaction Caused By Heavy Vehicles - A Long-Term Threat To Soil Productivity. Soil \& Tillage Research, 29, 105-110.

Hamza, M.A., andAnderson, W.K., 2005: Soil compaction in cropping systems: A review of the nature, causes and possible solutions. Soil and Tillage Research, 82, 121-145.

Lyster, R., 2012: Coal seam gas in the context of global energy and climate change scenarios. Environmental and Planning Law Journal, 29, 91-100.

Marinoni, O., Navarro Garcia, J., Marvanek, S., D., P., Clifford, D., andLaredo, L., 2012: Development of a system to produce maps of agricultural profit on a continental scale: An example for Australia. Agricultural Systems, 105, 33-45.

Queensland Government, 1994: Environmental Protection Act 1994, reprint as at 7 November 2014. 